\title{
Rare causes of emesis
}

Stefan L. Popa ${ }^{1}$, Giuseppe Chiarioni ${ }^{2}$, Liliana David ${ }^{1}$, George I. Golea ${ }^{1}$, Dan L. Dumitrascu ${ }^{1}$

1) $2^{\text {nd }}$ Medical Department, Iuliu Hatieganu University of Medicine and Pharmacy Cluj-Napoca, Romania

2) Division of Gastroenterology of the University of Verona, AOUI Verona, Italy and Division of Gastroenterology and Hepatology \& Center for Functional GI and Motility Disorders, University of North Carolina at Chapel Hill, Chapel Hill, $\mathrm{NC}$, USA
DOI: $10.15386 / \mathrm{mpr}-1509$

Manuscript received: 08.11.2019

Received in revised form: 20.02 .2020

Accepted: 05.03.2020

Address for correspondence:

popa.stefan@umfcluj.ro

This work is licensed under a Creative Commons Attribution-NonCommercialNoDerivatives 4.0 International License

\begin{abstract}
Prompt diagnosis in the emergency department in the case of a patient with emesis may be difficult due to the increasing prevalence of diseases which manifest with emesis. Furthermore, in the case of chronic symptomatology, management and therapy are even more complicated. One episode of emesis rarely causes complications, but severe or repetitive episodes of emesis can cause life-threatening complications. For this reason, the diagnosis of the underlying disease which manifests with emesis is mandatory to be established in a short time in order to choose the correct therapeutic option. In order to systemize the process of diagnosis, this clinical narrative review will discuss only rare causes of emesis.
\end{abstract}

Keywords: vomiting, Reye's syndrome, ackee poisoning, systemic mastocytosis, Meniere's disease, xanthinuria, hydrocephalus

\section{Introduction}

Emesis is a complex reflex, frequently preceded by increased salivation, and begins with involuntary retching and allows an animal or person to rid itself of ingested toxins or poisons [1,2]. Constriction of the abdominal muscles with the relaxation of the gastric cardia actively forces gastric contents back up the esophagus.

The medullary vomiting center is responsible for the coordination of the emesis reflex, which is influenced directly by afferent innervation, chemoreceptor trigger zone and other central nervous system centers. The most common causes of emesis are gastrointestinal disorders. Because almost all organs and systems can be involved in the pathogenesis of emesis, the diagnosis of the underlying disease may be difficult in some cases (Figure 1) [2] .

An essential step in the management of emesis is to make a distinction between acute versus chronic symptoms. Acute emesis is defined as episodic vomiting that occurs for less than one week and is associated with acute conditions. Chronic emesis is defined as a period of episodic vomiting longer than one week and is frequently associated with chemotherapy, functional gastrointestinal disorders, drugs, neurologic and neuropsychiatric disorders [1].
One episode of emesis rarely causes complications, but severe or repetitive episodes of emesis can cause life-threatening complications including: acid-base imbalance, dehydration and electrolyte depletion or aspiration pneumonia. For this reason, the diagnosis of the underlying disease which manifested with emesis is mandatory to be established in a short time in order to choose the correct therapeutic option $[1,2]$.

If the majority of gastrointestinal disorders manifested with emesis are easy to diagnose using standard techniques (blood tests, abdominal ultrasound, endoscopy or computer scan), several disorders deserve to be described in detail.

An essential step in the differential diagnosis of gastrointestinal disorders manifested with emesis is to clarify if the disorder is organic or functional [2].

Functional gastrointestinal disorders (FGID) are a highly prevalent group of disorders characterized by the lack of organic or chemical abnormalities, and the diagnosis is made using Rome IV Criteria, introduced in 2016 [2].

In this narrative review, we do not refer to rare diseases manifested with emesis; we refer to non-gastrointestinal rare causes of emesis (Table I). 


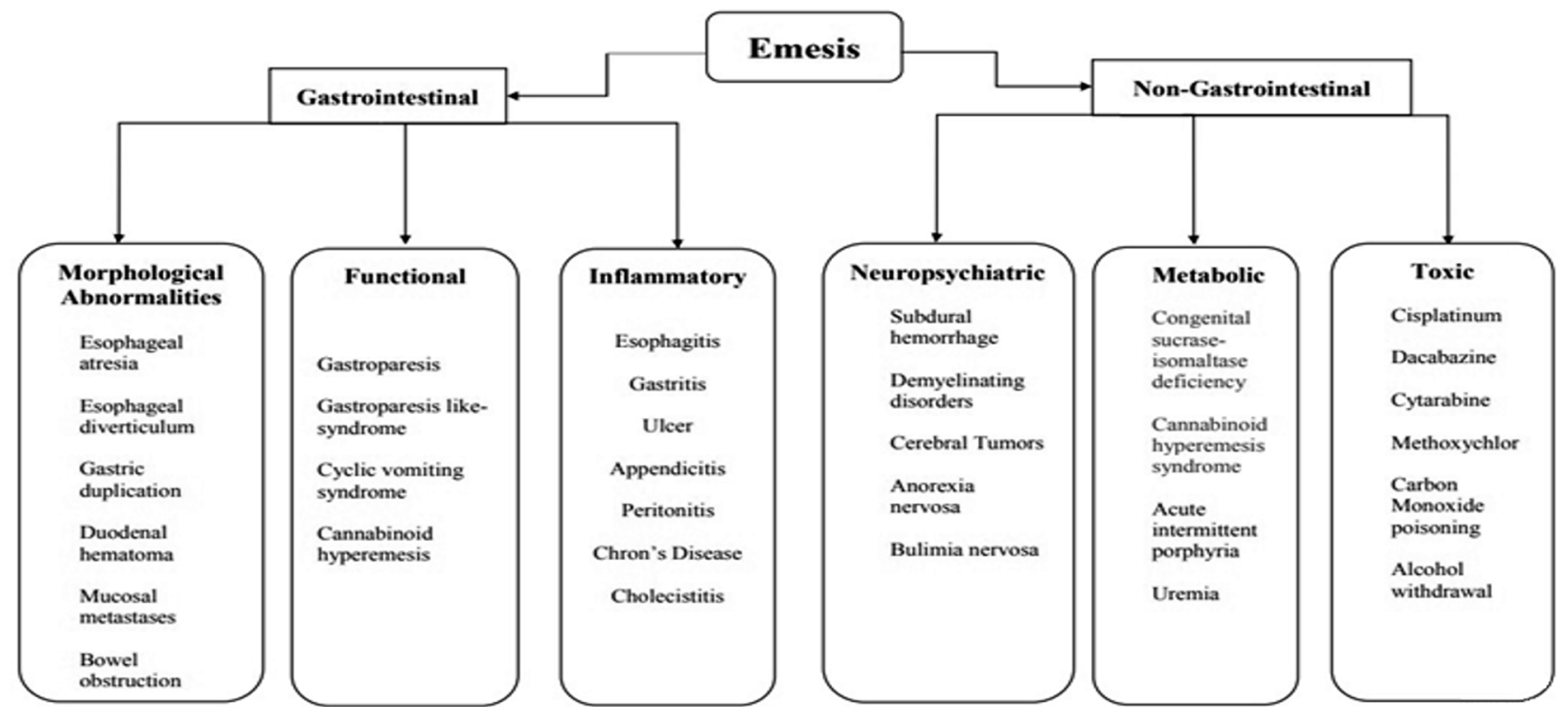

Figure 1. Causes of emesis.

Table I. Rare causes of emesis.

\section{Disease} Symptoms and signs

\section{Positive diagnosis}

$\begin{array}{ll} & \text { Vomiting } \\ \text { Reye's } & \text { Personality changes } \\ \text { Syndrome } & \text { Confusion } \\ & \text { Seizures } \\ & \text { Loss of consciousness }\end{array}$

$\begin{array}{ll} & \text { Diaphoresis } \\ \text { Ackee } & \text { Tachypnea } \\ \text { poisoning } & \text { Tachycardia } \\ & \text { Tonic-clonic convulsions } \\ & \text { Seizures }\end{array}$

Anemia and coagulopathy

Abdominal pain

Systematic Diarrhea

Mastocytosis Nausea

Vomiting

Pruritus and flushing

$\begin{array}{ll}\text { Meniere } & \text { Vertigo } \\ \text { Disease } & \text { Hearing loss } \\ & \text { Tinnitus } \\ & \text { Vomiting } \\ & \text { Irritability } \\ & \text { Vomiting } \\ \text { Xanthinuria } & \text { Hematuria } \\ & \text { Pyuria } \\ & \text { Renal colic } \\ & \text { Joint pain and muscle cramps } \\ & \text { Slowing of mental capacity } \\ & \text { Headaches } \\ \text { Hydrocephalus } & \text { Neck pain } \\ & \text { Blurred Vision } \\ & \text { Double vision } \\ & \text { Vomiting }\end{array}$

MRI: symmetric thalamic, basal ganglia and white matter lesions in children with a recent history of salicylates drug intake

Patient's history of eating ackee fruit

Profound hypoglycemia $<3 \mathrm{mg} / \mathrm{dl}$

Anemia

Thrombocytopenia

Leukocytosis

Monocytosis

Increased level of serum tryptase

Bone marrow biopsy: dense infiltrates of mast cells

Liver biopsy

Audiometry

Electrocochleography

Electronystagmography

Urine xanthine

Hypoxanthine levels

Ratio 4:1

Xanthine plasma levels between 10 and $40 \mu \mathrm{mol}$

Head Enlargement

Disjunction of sutures

Dilated scalp Vein

Papilledema
Treatment and management

Avoiding salicylates

Supportive care to treat: hyperammonemia- sodium benzoate/sodium phenylacetate IV

Hypoglycemia-dextrose 25\%

Acidosis-alkalinizing agents

Vomiting- ondansetron

Anticonvulsants- Lorazepam

Increased intracranial pressure- mannitol

Dextrose solution

Active Charcoal

Vomiting-Antiemetics

Seizures-Benzodiazepines

Primarily symptomatic

Management of

Anaphylaxis and related symptoms-epinephrine, $\mathrm{H} 1$ and H2 blocker, Corticosteroids

Pruritus and flushing- psoralen ultraviolet A therapy Intestinal malabsorption

Symptomatic relief

Vertigo- diazepam, steroids

Vestibulosuppressants and antinausea- meclizine, prochlorperazine

High fluid intake

Low purine diet

Avoiding dehydration

Treatment of complications

Decreasing the secretion by the choroid plexusacetazolamide and furosemide

Increasing the reabsorption of Cerebrospinal Fluid: Isosorbide

Repeated lumbar punctures

Choroid plexectomy

Choroid plexus coagulation

Ventriculoperitoneal shunt 


\section{Methods}

We examined articles in PubMed from 1999 to 2019, focused on rare causes of emesis. Keywords of the search were: "Emesis", "Vomiting", "Reye's Syndrome", "Ackee poisoning", "Systemic Mastocytosis", "Meniere's Disease", "Xanthinuria", "Hydrocephalus. Studies written in languages other than English, conference presentations, letters to the editor, editorials, comments, and opinions were also excluded.

\section{Results}

\section{Reye's syndrome}

Reye's syndrome is an acute disorder, potentially fatal, with a usual onset after a viral infection of the upper respiratory tract or gastroenteritis characterized by an acute encephalopathy associated with hepatic dysfunction in pediatric patients with a peak age between 5-14 years [3-5].

The complex pathogenesis of Reye syndrome is still not elucidated. Studies show that mitochondrial injury is directly implicated, resulting in several dysfunctions that disrupt oxidative phosphorylation and fatty-acid betaoxidation [3-6]. In at least $80 \%$ of the cases, the host has usually been exposed to mitochondrial toxins, most frequently salicylates.

Histopathological findings include cytoplasmic fatty vacuolization in hepatocytes, astrocyte edema and loss of neurons in the brain, and edema and fatty degeneration of the proximal lobules in the kidneys. Hepatic mitochondrial dysfunction results in hyperammonemia, which induces astrocyte edema, resulting in cerebral edema and increased intracranial pressure (ICP), which finally leads to severe emesis [3].

The viral infection (Influenza or Varicella are frequently reported) occurs 2 to 3 weeks before the symptomatology of Reye's Syndrome. The symptomatology is dominated by extended and abundant vomiting, headache, altered mental status (confusion, agitation, delirium), signs of dehydration (xerostomia, oliguria, fluid intolerance), and seizures.

The diagnosis is based on clinical signs in concordance with the laboratory findings, which include elevated glutamic-oxaloacetic transaminase, glutamic pyruvic transaminase, bilirubin, hypoglycemia, increased serum ammonia and decreased serum bicarbonate $[3,4]$.

If a spinal tap is performed, the cerebrospinal fluid contains a decreased level of leucocytes, demonstrating the absence of meningeal inflammation [3].

To evaluate cerebral edema, the recommendation is to perform a head computer scan (CT) or magnetic resonance imaging (MRI) in order to exclude other causes of encephalopathy. Frequently reported in MRI findings are the diffuse cerebral edema and symmetric signal modifications of white matter, thalamic and basal ganglia [3].

The management is an emergency because of the rapid progression, but it is still mainly supportive, its primary goals are to maintain hemodynamical stability and the oxygen saturation levels in optimal parameters [3-5].

The treatment consists in correcting the hypoglycemia with dextrose-containing fluids (serum glucose target $100-120 \mathrm{mg} / \mathrm{dl}$ ), the acidosis with sodium bicarbonate, mannitol of hypertonic saline fluids for cerebral edema, while increased ammonia levels will be treated with phenylacetate-sodium benzoate $[4,5]$. For severe increased intracranial pressure, mannitol or hypertonic (3\%) saline is currently used and hypertonic saline should not be given to patients with elevated levels of sodium [5-7].

\section{Ackee fruit poisoning}

Ingestion of Blighia Sapida, known as ackee fruit [8], originally from West Africa and Central America, can lead to metabolic syndrome, generally known as Jamaican vomiting sickness [9]. The unripened fruit may lead to profuse vomiting, convulsions, seizures, hypoglycemia and coma. The main toxin found in the seeds is called hypoglycin B, a hypoglycemic substance.

Recent studies show that a high risk for ackee poisoning is represented by the consumption of unripe ackee fruit or reuse of the water in which an unripe ackee has been cooked or washed.

Since 1976, over 500 poisonings have been linked to ackee fruit in Jamaica and other countries, and more than 100 cases of acute illness and death were reported $[9,10]$.

Toxicity is dose dependent; the first symptoms appear in the 6-48 hours of ingestion and the recovery appears after 7-20 days. In fatal cases, death usually occurs within 48 hours of ingestion and severe hypoglycemia, hepatic injury, and aciduria are responsible for exitus.

Laboratory findings are identical with those from Reye's syndrome (hypoglycemia, hyperammonemia, metabolic acidosis), but glutaric and ethylmalonic acid levels increase in urine [10]. The treatment is supportive, and its primary goals are to maintain the euglycemia by giving boluses of dextrose to prevent dehydration by giving IV fluids and antiemetics and securing an airway $[9,10]$. Riboflavin and glycine are in some severe cases useful in therapy as they have been found to antagonize the effects of hypoglycin A intoxication [9].

Neurological symptoms can be treated with benzodiazepines. At the moment, there is no antidote for ackee fruit toxins [9]. Before modern therapies were developed, the mortality rate was more than $80 \%$. With treatment, most patients make a full recovery.

\section{Systemic mastocytosis}

Systemic mastocytosis is a subcategory of myeloproliferative neoplasms that consists of an abnormal increase of mastocytes that affects an extracutaneous organ, frequently the bone marrow. There are two types of mastocytosis, the systemic and the cutaneous, which affects only the skin [11]. The clinical presentation has a 
broad spectrum, from only a maculopapular lesion in the cutaneous type usually in pediatric patients, to a more aggressive form, systemic mastocytosis, that includes multiple organ failure [12].

Median survival ranges from 198 months in patients with indolent systemic mastocytosis, 41 months in aggressive systemic mastocytosis, and 2 months in mast cell leukemia. The most important procedure used in the process of diagnosis includes: bone marrow aspiration and biopsy, gastroscopy and colonoscopy, liver biopsy can show mast cell infiltration in patients with hepatomegaly, skin biopsy.

The major diagnostic criteria for systemic mastocytosis is the presence of dense infiltrates of mast cells in bone marrow or other extracutaneous tissues. Mast cells should be seen in aggregates of 15 or more [11-13].

Major criteria may be absent in early disease. In this situation, the minor criteria are used to make the pathologic diagnosis. Three of the following four minor criteria are required to make the diagnosis [12]:

I. Atypical mast cell morphology in $25 \%$ or more of the mast cells

II. Expression of CD2 and/or CD25 in addition to normal mast cell markers $\mathrm{ng} / \mathrm{mL}$

III. Serum/plasma tryptase levels greater than 20

IV. A codon-816 c-kit mutation in peripheral blood, bone marrow, or involved tissue

The symptomology of systemic mastocytosis includes pruritus, abdominal pain, nausea, vomiting, diarrhea, headache, depression, hypotension, osteoporosis. For the diagnosis, World Health Organization elaborated extended criteria that include morphological modification of the mastocytes, immunophenotypically abnormalities and genetic criteria [11].

The treatment is individualized, based on molecular abnormalities. Currently, the therapy in systemic mastocytosis is palliative with its main focus is to reduce symptomatology. Interferon $\alpha$ in systemic mastocytosis is often considered first-line treatment, showing an improvement in the gastrointestinal, hematological and dermatological symptomatology caused by the increased histamine release [13]. Administration of beta-blockers and alpha blockers is contraindicated in patients who are undergoing surgery because these agents interfere with epinephrine and can lead to anaphylaxis [14].

$\mathrm{H} 1$ antagonists (diphenhydramine and hydroxyzine) are currently used to treat pruritus, and flushing and H2 receptor blockers are frequently used to treat gastric hypersecretion and peptic ulcer disease associated with systemic mastocytosis. Proton pump inhibitors are used if nausea, vomiting and epigastric pain are not responsive to other pharmacological agents [14]. Chemotherapy has been used in the treatment of category II-IV systemic mastocytosis but has not been particularly successful as a therapeutical option in this disease $[13,14]$.

\section{Meniere's disease}

Meniere's disease is a pathology of the inner ear, affecting patients between 40 to 60 years old [15] and consists of spontaneous peripheral vertigo, tinnitus, alternating hearing loss, vomiting, and a fullness sensation in one or both ears [16]. It is considered to be a multifactorial disease with a strong genetic background [17]. This disease can affect one or both ears.

A specific feature frequently reported is the endolymphatic hydrops, which consists of an overflowing accumulation on endolymph in the inner ear, cochlea, and the semicircular channels, damaging the ganglion cells [18-19]. The diagnosis is established by using the patient's medical history associated with a complex set of test including [19-22]:

I. Audiometry

II. Brainstem auditory evoked potentials

III. Electrocochleography (ECOG)

IV. Otoscopy

V. Caloric testing/electronystagmography (ENG)

Usually, patients with a suspicion of Ménière disease are not submitted imaging studies, but the differential diagnosis with brain cancer or stroke is difficult, therefore magnetic resonance imaging (MRI) or computed tomography (CT) is indicated.

The disease can be classified into several stages of progression. The first stage includes cochlear hydrops, which proceeds to affect the vestibular system. This is the reason why Ménière's disease is most bothersome in the early stages. As the disease progresses to advanced stages, the hydrops fills the vestibule completely, pressure fluctuation ceases and consequently vertigo disappears [15-18]. The acute attacks are replaced by constant imbalance and progressive hearing loss. Episodes may occur as infrequently as once or twice a year or they may occur everyday. The prognosis of patients varies and some patients have minimal symptoms and others have severe symptomatology [15-20].

The management consists in reducing the symptoms, prevent the recurrence, and also the progression of the disease. For the treatment of the vertigo attacks, there are a few pharmacological possibilities. Antihistaminic agents acting on central receptors have a dual effect, anti-emetics and diminishing the vestibular syndrome [21]. GABA agonist agents, benzodiazepines (lorazepam diazepam) are also an option for the treatment of the acute vertigo attacks.

Surgical treatment is required for $5-10 \%$ of patients and consists of endolymphatic sac decompression associated with shunt placement [22-25]. Another treatment option is ablation, consisting of destruction of the labyrinth or the vestibular nerve, which will make the affected ear unresponsive to sense movement anymore, therefore, to stop vertigo [23-25]. 


\section{Xanthinuria}

Xanthinuria is a pathology based on an abnormal purine metabolism, characterized by the insufficiency of xanthine dehydrogenase/oxidase [26]. This rare autosomal recessive disorder characterized by the enzymatic deficiency of xanthine dehydrogenase/oxidase (which is involved in the conversion of the xanthine and hypoxanthine to uric acid) leads to low or even absent levels of uric acid ( $<1 \mathrm{mg} /$ $\mathrm{dL}$ ) and increased levels of xanthine levels in blood and urine. Patients can be asymptomatic or can have symptoms due to renal stones, frequently radiolucent, which can lead to kidney failure.

Xanthinuria can be subcategorized in three forms: type I with xanthine dehydrogenase deficiency, type II xanthine dehydrogenase, and aldehyde oxidase deficiencies, type III that includes both type II deficiency and molybdenum cofactor deficiency. To distinguish between Type I and Type 2, allopurinol test is performed. For Type 3, the laboratory findings show an increased urinary excretion of sulfur-containing metabolites [27]. The treatment consists of a restrictive diet with a low intake of purines and low fructose and a high intake of fluids.

\section{Hydrocephalus}

Hydrocephalus is a brain condition in pediatric patients that can be either acquired or congenital and consists of the expansion of the cerebral ventricles due to a modification of the cerebral spinal fluid physiology. A large part of children with congenital hydrocephalus has Aqueduct of Sylvius stenosis, holoprosencephaly or other brain malformations [28].

Hydrocephalus can be divided into obstructive and communicating. An intracranial mass (tumor, cyst) or congenital malformations can cause obstruction leading to the obstructive type. The communicating hydrocephalus can have multiple causes such as infections, intraventricular hemorrhage following an acute stroke, sinus thrombosis $[28,29]$.

Acquired hydrocephalus develops due to brain tumors, posttraumatic or impaired venous drainage. The symptomatology depends on the age of the patient and consists in symptoms related to increased intracranial pressure: headache, vomiting without nausea, ataxia. In children with open sutures, the head circumference will expand [28-30].

Clinical signs corroborated with the paraclinical findings (ultrasonography, MRI, computed tomography) or cerebrospinal fluid pressure measurements can lead to the diagnosis of hydrocephalus [29-33].

In pediatric patients, a sign of increased intracranial pressure is represented by the protrusion of the frontal fontanelle. The symptomatology depends on the age of the patient and consists of symptoms associated with an increased intracranial pressure: headache, emesis, diplopia due to VI cranial nerve palsy and ataxia.
Ultrasound in the early stages of fetal development, in 18-20 weeks' gestation, can identify ventriculomegaly [29]. MRI is preferred over CT to avoid radiation exposure, and it can show the cause and anatomy. The standard treatment is cerebral spinal fluid shunts. A ventriculoperitoneal shunt is frequently used, but other drainage CSF sites are also used: right atrium, pleural cavity. The other treatment solution is Endoscopic Third Ventriculostomy and cauterization of the choroid plexus [30].

The type of treatment is indicated based on the etiology of the hydrocephalus. For secondary hydrocephalus, the shunting or ventriculostomy may not be necessary if the cause is removed [32-34]. The standard treatment is the CSF shunting. The most frequent technique is the ventriculo-peritoneal shunt but other distal sites can be used for drainage (right atrium, pleural cavity) [29-33]. In aqueduct of Sylvius Stenosis, Endoscopic Third Ventriculostomy is recommended or as the solution in shunt failure and Chiari malformation [32-35]. Choroid plexus cauterization can also be associated with this operation.

\section{Conclusions}

A thorough understanding of the central and peripheral pathophysiology underlying emesis is essential for the optimal management of this disabling and complex symptom. However, treatments available are not effective in all patients, and the unmet need for a tailored approach would benefit from the development of novel, etiology focused therapies.

\section{References}

1. Becker DE. Nausea, vomiting, and hiccups: a review of mechanisms and treatment. Anesth Prog. 2010;57:150-156; quiz 157.

2. Popa SL, Chiarioni G, David L, Golea GI, Dumitrascu DL. Functional Emesis. J Gastrointestin Liver Dis. 2019;28:319325.

3. Gallucci M, Smith JD, Limbucci N, Rossi A, Demaerel P, Krings $\mathrm{T}$, et al. Pediatric Inflammatory Diseases. Part IV: Miscellaneous, Reye, PRES, Sarcoidosis. Neuroradiol J. 2012;25:725-738.

4. Belkengren RP, Sapala S. Reye syndrome: clinical guidelines for practitioners in ambulatory care. Pediatr Nurs. 1981;7:2628.

5. Brannelly NT, Hamilton-Shield JP, Killard AJ. The Measurement of Ammonia in Human Breath and its Potential in Clinical Diagnostics. Crit Rev Anal Chem. 2016;46:490501.

6. Schrör K. Aspirin and Reye syndrome: a review of the evidence. Paediatr Drugs. 2007;9:195-204.

7. Glasgow JF, Middleton B, Moore R, Gray A, Hill J. The mechanism of inhibition of beta-oxidation by aspirin 
metabolites in skin fibroblasts from Reye's syndrome patients and controls. Biochim Biophys Acta. 1999;1454:115-125.

8. Sanford AA, Isenberg SL, Carter MD, Mojica MA, Mathews TP, Laughlin S, et al. Quantification of hypoglycin A and methylenecyclopropylglycine in human plasma by HPLCMS/MS. J Chromatogr B Analyt Technol Biomed Life Sci. 2018;1095:112-118.

9. Katibi OS, Olaosebikan R, Abdulkadir MB, Ogunkunle TO, Ibraheem RM, Murtala R. Ackee Fruit Poisoning in Eight Siblings: Implications for Public Health Awareness. Am J Trop Med Hyg. 2015;93:1122-1123.

10. Joskow R, Belson M, Vesper H, Backer L, Rubin C. Ackee fruit poisoning: an outbreak investigation in Haiti 20002001, and review of the literature. Clin Toxicol (Phila). 2006;44:267-273.

11. Baumann I. WHO classification of tumors of haematopoetic and lymphoid tissues. Juvenile Myelomonocytic Leukaemia 2008: 82-844.

12. Lim KH, Tefferi A, Lasho TL, Finke C, Patnaik M, Butterfield JH, et al. Systemic mastocytosis in 342 consecutive adults: survival studies and prognostic factors. Blood. 2009; 113:5727-5736.

13. Pardanani A. Systemic mastocytosis in adults: 2017 update on diagnosis, risk stratification and management. Am J Hematol. 2016;91:1146-1159.

14. Bunimovich O, Grassi M, Baer MR. Systemic mastocytosis: classification, pathogenesis, diagnosis, and treatment. Cutis. 2009;83:29-36.

15. Vassiliou A, Vlastarakos PV, Maragoudakis P, Candiloros D, Nikolopoulos TP. Meniere's disease: Still a mystery disease with difficult differential diagnosis. Ann Indian Acad Neurol. 2011;14:12-18.

16. Nakashima T, Pyykkö I, Arroll MA, Casselbrant ML, Foster CA, Manzoor NF, et al. Meniere's disease. Nat Rev Dis Primers. 2016;2:16028.

17. Morrison AW, Johnson KJ. Genetics (molecular biology) and Meniere's disease. Otolaryngol Clin North Am. 2002;35:497516.

18. Hallpike CS, Cairns H. Observations on the pathology of Ménière's syndrome. J Laryngol Otol. 1938;53:625-655.

19. Yamakawa, K. Über die patologische Veränderungen bei einem Menière-kranken. J Otorhinolaryngol. Soc Jpn. 1938;44, 2310-2312.

20. Tyrrell JS, Whinney DJ, Ukoumunne OC, Fleming LE, Osborne NJ. Prevalence, associated factors, and comorbid conditions for Ménière's disease. Ear Hear. 2014;35:e162-e169.

21. Lauter JL, Lynch O, Wood SB, Schoeffler L. Physiological and behavioral effects of an antivertigo antihistamine in adults. Percept Mot Skills. 1999;88:707-732.
22. Thomsen J, Bonding P, Becker B, Stage J, Tos M. The nonspecific effect of endolymphatic sac surgery in treatment of Meniere's disease: a prospective, randomized controlled study comparing "classic" endolymphatic sac surgery with the insertion of a ventilating tube in the tympanic membrane. Acta Otolaryngol. 1998;118:769-773.

23. Sood AJ, Lambert PR, Nguyen SA, Meyer TA. Endolymphatic sac surgery for Ménière's disease: a systematic review and meta-analysis. Otol Neurotol. 2014;35:1033-1045.

24. Kıroğlu O, Sürmelioğlu Ö, Kıroğlu M. Effects of Selective Seratonine Re-Uptake Inhibitors on Meniere's Disease. J Int Adv Otol. 2017;13:276-278.

25. Gates G. Ménière's disease: medical therapy. Harris JP, ed. Ménière's Disease. The Hague, Netherlands: Kugler publications; 1999, pp. 329-340.

26. Mraz M, Hurba O, Bartl J, Dolezel Z, Marinaki A, Fairbanks L, et al. Modern diagnostic approach to hereditary xanthinuria. Urolithiasis. 2015;43:61-67.

27. Agarwal A, Banerjee A, Banerjee UC. Xanthine oxidoreductase: a journey from purine metabolism to cardiovascular excitation-contraction coupling. Crit Rev Biotechnol. 2011;31:264-280.

28. Liew BS, Takagi K, Kato Y, Duvuru S, Thanapal S, Mangaleswaran B. Current Updates on Idiopathic Normal Pressure Hydrocephalus. Asian J Neurosurg. 2019;14:648-656.

29. Garne E, Loane M, Addor MC, Boyd PA, Barisic I, Dolk H. Congenital hydrocephalus - prevalence, prenatal diagnosis and outcome of pregnancy in four European regions. Eur J Paediatr Neurol. 2010;14:150-155.

30. Tully HM, Dobyns WB. Infantile hydrocephalus: a review of epidemiology, classification and causes. Eur J Med Genet. 2014;57:359-368.

31. Burstein J, Papile LA, Burstein R. Intraventricular hemorrhage and hydrocephalus in premature newborns: a prospective study with CT. AJR Am J Roentgenol. 1979;132:631-635.

32. Robinson S. Neonatal posthemorrhagic hydrocephalus from prematurity: pathophysiology and current treatment concepts. J Neurosurg Pediatr. 2012;9:242-258.

33. Quencer RM. Intracranial CSF flow in pediatric hydrocephalus: evaluation with cine-MR imaging. AJNR Am J Neuroradiol 1992;13:601-608.

34. Anik I, Etus V, Anik Y, Ceylan S. Role of interpeduncular and prepontine cistern cerebrospinal fluid flow measurements in prediction of endoscopic third ventriculostomy success in pediatric triventricular hydrocephalus. Pediatr Neurosurg. 2010;46:344-350.

35. Kahle KT, Kulkarni AV, Limbrick DD Jr, Warf BC. Hydrocephalus in children. Lancet. 2016;387:788-799. 